\title{
VARIACIÓN EN CARACTERÍSTICAS REPRODUCTIVAS Y GERMINACIÓN DE SEMILLAS DE Pinus leiophylla Schiede ex Schltdl. \& Cham.
}

\author{
VARIATION IN REPRODUCTIVE TRAITS AND GERMINATION \\ OF Pinus leiophylla Schiede ex Schltdl. \& Cham.
}

\author{
Dorian M. Gómez Jiménez ${ }^{1}$, Carlos Ramírez Herrera ${ }^{2}$, Jesús Jasso Mata² y Javier López Upton²
}

\author{
${ }^{1}$ Gerencia Regional XI, Comisión Nacional Forestal (CONAFOR). Tuxtla Gutiérrez, Chiapas, México. ${ }^{2}$ Postgrado Forestal, Colegio de Postgraduados- \\ Campus Montecillo. Km. 36.5 Carr. México-Texcoco. 56230, Montecillo Texcoco, Edo. de México. Tel. 01(595)952-0200, ext. 1463. \\ *Autor para correspondencia (kmcram@colpos.mx, kmcramcolpos@gmail.com)
}

\section{RESUMEN}

En el presente estudio se determinó la variación existente en características reproductivas y la germinación de la semilla cosechada en árboles de Pinus leiophylla Schiede ex Schltdl. \& Cham. en un huerto semillero sexual. Se midió el peso seco de 20 estróbilos maduros por árbol. Se determinaron las variables: número potencial de semillas; porcentajes de semillas desarrolladas, de semillas llenas, de semillas vanas y de óvulos abortivos; peso promedio de la semilla; índice de endogamia y eficiencia reproductiva por estróbilo. La semilla se germinó sobre tela en cajas de plástico, en una cámara de ambiente controlado. Se encontraron diferencias significativas entre árboles para las variables evaluadas. El peso seco promedio del estróbilo fue $15.2 \mathrm{~g}$. El número potencial promedio de semillas por estróbilo fue 108, de las cuales 63.7, 17.7 y $18.6 \%$ fueron óvulos abortivos, semillas llenas y semillas vanas, respectivamente. El peso promedio de una semilla fue $11.6 \mathrm{mg} \mathrm{(86} 200$ semillas por $\mathrm{kg}$ ). El índice promedio de endogamia (0.50) indica un alto nivel de autofecundación. Se encontró una eficiencia reproductiva de $15.9 \mathrm{mg}$ de semilla por gramos de estróbilo. La semilla mostró calidad alta en: capacidad germinativa (82.5\%), valor pico promedio (8.5) y el valor germinativo promedio (29.4). Los árboles contribuyeron con 41.3, 29.3 y $36.9 \%$ de la variación total para capacidad germinativa, valor pico $y$ valor germinativo, lo que indica una alta variación genética en las características reproductivas y parámetros genéticos. A pesar del alto índice de endogamia y del bajo porcentaje de semillas llenas por estróbilo, los árboles de $P$. leiophylla en el huerto semillero produjeron semilla llena de alta calidad, de acuerdo con los resultados de germinación.

Palabras clave: Pinus leiophylla, capacidad germinativa, depresión endogámica, huerto semillero.

\section{SUMMARY}

Variability in reproductive traits and seed germination in a seed orchard of Pinus leiophylla Schiede ex Schltdl. \& Cham. was determined. The dried weight of each of 20 cones per tree was measured. The number of variables registered were: potential seeds, percentages of filled and empty seeds, percentage of abortive ovules, average weight per seed, inbreeding depression index and reproduc-

Recibido: 19 de Abril del 2010.

Aceptado: 21 de Julio del 2010. tive efficiency. Seeds were germinated on dumped cloth in plastic boxes set in a germination chamber. There were significant differences among trees for all included traits. The overall average of a dried cone weight was $15.2 \mathrm{~g}$. The mean number of potential seeds per cone was 108. The percentage of abortive ovules was 63.7 $\%$ of the seed potential. Filled and empty seeds represented $17.7 \%$ and $18.6 \%$ of the seed potential, respectively. The average weight per seed was $11.6 \mathrm{mg}(86200$ seeds per $\mathrm{kg})$. The average inbreeding depression index $(0.50)$ showed a high self-fertilization rate. The reproductive efficiency was $15.9 \mathrm{mg}$ of seed per gram of cone. The germination capacity $(82.5 \%)$, peak value $(8.5)$ and germination value (29.4) revealed a high seed quality. Trees contributed with 41.3, 29.3 and $36.9 \%$ for germination capacity, peak value, and germination value, respectively, to the total variation, thus indicating high genetic variability for germination parameters and reproductive traits. In spite of the high inbreeding depression and the low number of filled seeds, the trees in the $P$. leiophylla orchard were able to produce sound seeds of high quality, according to germination results.

Index words: Pinus leiophylla, germination capacity, inbreeding depression, seed orchard.

\section{INTRODUCCIÓN}

Pinus leiophylla Schiede ex Schltdl. \& Cham. es una especie de importancia ecológica y económica que crece en poblaciones naturales distribuidas desde el Estado de Chihuahua hasta el Estado de Oaxaca, a altitudes de 1600 a $3000 \mathrm{~m}$ (Perry, 1991). Los productos que se obtienen de esta especie son básicamente resina, pulpa y madera para construcción (Perry, 1991). Los incendios forestales y el cambio de uso del suelo para el establecimiento de cultivos agrícolas y frutícolas han sido la principal causa de destrucción de poblaciones conformadas con árboles de esta especie. $P$. leiophylla debería ser considerada como una alternativa en los programas de reforestación en el país debido a su importancia en algunos ecosistemas y por la capacidad de las plántulas de esta especie para 
sobrevivir y crecer en condiciones de humedad restringida (Martínez-Trinidad et al., 2002).

Este pino rara vez forma rodales puros (Perry, 1991), y crece en poblaciones aisladas y de baja densidad. La escasa disponibilidad de semilla de calidad puede ser un factor limitante, agravado por la periodicidad de la producción de semilla de los árboles en bosques naturales. Los huertos semilleros constituyen una alternativa para la producción de semilla de calidad en el establecimiento de plantaciones en México. Estas unidades productoras de germoplasma se establecen con plantas provenientes de árboles fenotípicamente superiores, los cuales pueden tener genes que influyan en forma positiva en características deseables (White et al., 2007). Los huertos semilleros en especies forestales permiten una mejor planeación de las plantaciones, y reducen la necesidad de recolectar germoplasma en bosques naturales (Griffin, 1990). Los huertos semilleros son útiles para conservar individuos sobresalientes, los cuales pueden ser importantes en la restauración de poblaciones naturales (White et al., 2007). Además, en ellos la producción de semilla puede incrementarse mediantes prácticas como fertilización, irrigación y aplicación de hormonas (Cherry et al., 2007).

P. leiophylla es una especie monoica, en la que un árbol sexualmente maduro produce estróbilos masculinos y femeninos, por lo que la probabilidad de autofecundación es alta, como se ha observado en el género Pinus (Williams, 2008). La semilla y el polen de las coníferas son dispersados por el viento, y aunque éste puede transportarlos a distancias considerables, la mayoría de semillas y polen alcanzan distancias menores a $10 \mathrm{~m}$ del árbol, de modo que se establecen grupos de árboles emparentados y se promueve el cruzamiento entre éstos (Vander Wall, 1992; Burczyka et al., 2004).

El cruzamiento de árboles emparentados y la autofecundación aumenta la probabilidad de que la descendencia contenga genes que provienen de ancestros comunes, proceso conocido como endogamia (Hart y Clark, 2007). La endogamia aumenta la frecuencia de individuos homocigóticos los cuales pueden ser menos competitivos que los heterocigóticos, particularmente en ambientes adversos, debido a la acción en estado homocigótico de alelos deletéreos o parcialmente deletéreos, fenómeno común en coníferas (Crnokrak y Barrett, 2002; Hart y Clark, 2007). La disminución de la capacidad adaptativa de los organismos debido a la endogamia se conoce como depresión endogámica, la cual pone en riesgo la viabilidad de poblaciones pequeñas (Hart y Clark, 2007). En coníferas la depresión endogámica genera semilla vana, mortalidad alta en etapas tempranas de desarrollo como en la germinación, y tasas de crecimiento menores al promedio (Mosseler et al., 2000; Remington y O’Malley, 2000).

Entender los factores que influyen en la variación en características reproductivas y la germinación de semilla es fundamental en el manejo de las unidades productoras de germoplasma y en la planeación de las plantaciones, por lo que en este estudio se plantearon dos objetivos: determinar el patrón de variación existente en características reproductivas, y evaluar la germinación de la semilla cosechada en árboles de $P$. leiophylla en un huerto semillero sexual.

\section{MATERIALES Y MÉTODOS}

\section{Germoplasma}

El estudio se hizo en el huerto semillero constituido por 96 árboles, de $P$. leiophylla ubicado entre las coordenadas geográficas $19^{\circ} 27^{\prime} 34.8^{\prime \prime}$ LN y $98^{\circ} 54^{\prime} 15.8^{\prime \prime}$ LO, a una altitud de 2249 m, en Texcoco, Estado de México. El clima del área es templado con lluvias en verano con una precipitación media anual de $559 \mathrm{~mm}$ y temperatura media anual de $15.3{ }^{\circ} \mathrm{C}$ (Estación Meteorológica Montecillo). El tipo de suelo es Solonchak-Gleyico (Dirección General de Geografía, 1983). El huerto se estableció en 1991 con los mejores individuos que originalmente constituían parte de un estudio de procedencias-progenies establecido en 1989. La semilla que originó las plantas del huerto semillero fue recolectada en 16 poblaciones naturales de esta especie, localizadas en los Estados de México, Tlaxcala, Puebla y Distrito Federal.

Los árboles del huerto fueron seleccionados con base en altura, color y apariencia sana del follaje, y están completamente aislados de cualquier población natural de $P$. leiophylla, por lo que es nula la contaminación proveniente de polen por otros árboles de este pino. A mediados de marzo se da un riego de auxilio, y en la temporada de lluvias se controla las malezas y el pasto. En 2008 únicamente 28 de los 96 árboles del huerto produjeron estróbilos, y de ellos se utilizaron los 20 árboles con la producción más alta. Los estróbilos se colocaron en bolsas de papel debidamente identificadas con el número del árbol, y luego se seleccionaron al azar 20 estróbilos por árbol, que se colocaron en un invernadero para provocar la apertura de las escamas. Después de extraer la semilla y contar las escamas fértiles de los estróbilos, éstos se secaron en un horno eléctrico (FX14®, Shel Lab) a $109{ }^{\circ} \mathrm{C}$ por $18 \mathrm{~h}$ (Mosseler et al., 2000). El peso seco de los estróbilos se determinó en 
gramos en una balanza electrónica $(0.1 \mathrm{~g}, \mathrm{~N} 08110 \AA$, OHAUS Corporation).

\section{Características reproductivas}

El número potencial de semillas se obtuvo al multiplicar por dos el número de escamas fértiles (Mosseler et al., 2000), y se contó el número de semillas vanas y llenas por estróbilo, las que se separaron mediante una columna de viento (sin marca). El número de óvulos abortivos por estróbilo se estimó al restar el número de semillas formadas del número potencial de semillas. El índice de depresión endogámica se consideró como la proporción del número de semillas vanas con respecto al total de las desarrolladas (Mosseler et al., 2000). El total de semillas llenas se pesó en una balanza analítica ( $\mathrm{SM} \circledast$, Chyo Balance Corporation). El peso promedio de una semilla llena se calculó con el peso de las semillas llenas dividido entre el número de éstas. La eficiencia reproductiva se calculó como el cociente del peso de las semillas llenas entre el peso seco del estróbilo (Mosseler et al., 2000).

\section{Ensayo de germinación}

Se utilizó una muestra de 300 semillas llenas de cada uno de los 20 árboles, que se distribuyeron en un diseño en bloques al azar con 20 repeticiones (15 semillas por repetición). Las semillas se germinaron sobre tela absorbente (paño multiusos, Ultra Celtix ${ }^{\circledR}$ ) en cajas de plástico de $20 \times 26 \mathrm{~cm}$. La tela absorbente se humedeció con $250 \mathrm{~mL}$ de agua potable, y las cajas de plástico con las semillas se colocaron en una cámara de ambiente controlado (SM ${ }^{\circledR}$, Lab-Line Instruments, Inc.) a $25{ }^{\circ} \mathrm{C}$. Diariamente se contaron las semillas germinadas durante $25 \mathrm{~d}$.

\section{Análisis estadísticos}

Los datos para las características de estróbilos fueron analizados con el procedimiento GLM-SAS/PC para Windows versión 9.1.3 (SAS Institute, 2003) con el modelo siguiente:

$$
Y_{i j}=\mu+A_{i}+\xi_{i j}
$$

Donde: $Y_{i j}$ es la observación $j$-ésima del árbol $i, \mu$ es la media experimental, $A_{i}$ es el efecto del $i$-ésimo árbol, y $\xi_{i j}$ es el error experimental.

Los datos de capacidad germinativa se transformaron con la función arcoseno de la raíz cuadrada de $p(\theta=$ $\operatorname{arcoseno} \sqrt{p}$, donde $\theta$ es el dato transformado y $p$ es la capacidad germinativa sin transformar) para así mejorar su distribución normal (Sokal y Rohlf, 1981). Las variables que se consideraron fueron: como medidas de vigor de la semilla (Czabator, 1962; Kolotelo et al., 2001), capacidad germinativa, valor pico y valor germinativo. La capacidad germinativa es el porcentaje final de germinación. El valor pico es el valor máximo de la sumatoria del porcentaje de germinación dividido por el número de días y representa la velocidad de germinación (Kolotelo et al., 2001). El valor germinativo es el valor pico multiplicado por la germinación promedio (Kolotelo et al., 2001). Se utilizó el procedimiento GLM del paquete SAS, con el modelo:

$$
Y_{i j}=\mu+R_{i}+A_{j}+\xi_{i j}
$$

Donde: $R i$ es el efecto de la $i$-ésima repetición.

Los componentes de varianza se estimaron con el procedimiento VARCOMP-SAS/PC (REML).

\section{RESULTADOS}

\section{Características reproductivas}

Se encontraron diferencias $(\mathrm{P} \leq 0.01)$ entre árboles para las variables de estróbilos y de semillas de $P$. leiophylla (Cuadro 1). La varianza entre árboles fue la principal fuente de variación en la mayoría de las características. El peso promedio de los estróbilos fue $15.2 \mathrm{~g}$, y varió de 7.9 a $24.9 \mathrm{~g}$ en los árboles 109 y 73, respectivamente (Cuadro 2). El número potencial promedio de semillas por estróbilo de $P$. leiophylla fue de 108 , con valores promedios extremos de 90 y 128 en los árboles 61 y 73, respectivamente.

Los porcentajes promedio de óvulos abortivos, semillas llenas y vanas fueron $63.7,17.7$ y $18.6 \%$ del potencial de semillas, respectivamente. Los porcentajes de óvulos abortivos variaron de $34 \%$ en el árbol 51, a $86 \%$ en el árbol 98 (Cuadro 2). La diferencia entre los porcentajes extremos (árboles 98 y 51) para semillas vanas fue $35 \%$. El peso promedio de una semilla de $P$. leiophylla fue 11.6 mg y varió de $8.8 \mathrm{mg}$ (árbol 105) a $15.9 \mathrm{mg}$ (árbol 73). El índice promedio de depresión endogámica fue $0.50 \mathrm{y}$ varió de 0.21 en el árbol 98 a 0.83 en el árbol 168 . La eficiencia reproductiva promedio fue $16 \mathrm{mg}$ de semilla por gramo de cada estróbilo, y los valores extremos de la eficiencia fueron encontrados en el árbol 133 con $3 \mathrm{mg} \mathrm{g}^{-1}$ y $47 \mathrm{mg} \mathrm{g}^{-1}$ en el árbol 92. 
Cuadro 1. Componentes de varianza para las características reproductivas de estróbilos de un huerto semillero sexual de Pinus leiophylla Schiede ex Schltdl. \& Cham.

\begin{tabular}{lccc}
\hline Características & $\sigma^{2}$ Total & \multicolumn{2}{c}{ Componentes de varianza (en \% de la $\sigma^{2}$ Total) } \\
\cline { 3 - 4 } & & $\sigma^{2}$ Arbol & $\sigma^{2}$ Error \\
\hline Peso seco del estróbilo & 35.34 & $73^{* *}$ & 27 \\
Num. potencial de semillas & 315.37 & $52^{* *}$ & 48 \\
Porcentaje de óvulos abortivos & 356.91 & $55^{* *}$ & 45 \\
Porcentaje de semillas llenas & 153.93 & $54^{* *}$ & 46 \\
Porcentaje de semillas vanas & 186.47 & $48^{* *}$ & 52 \\
Peso promedio de una semilla & 3.69 & $75^{* *}$ & 25 \\
Índice de endogamia & 0.06 & $45^{* *}$ & 55 \\
Eficiencia reproductiva & 186.42 & $63^{* *}$ & 37 \\
\hline
\end{tabular}

** $\mathrm{P} \leq 0.01$

Cuadro 2. Medias ( \pm error estándar) de características reproductivas de estróbilos de un huerto semillero de Pinus leiophylla Schiede ex Schltdl. \& Cham.

\begin{tabular}{|c|c|c|c|c|c|c|c|c|}
\hline Árbol & $\begin{array}{l}\text { Peso seco del } \\
\text { estróbilo (g) }\end{array}$ & $\begin{array}{l}\text { Núm. potencial } \\
\text { de semillas }\end{array}$ & $\begin{array}{l}\text { POA } \\
(\%)\end{array}$ & $\begin{array}{l}\text { PSLL } \\
(\%)\end{array}$ & $\begin{array}{l}\text { PSV } \\
(\%)\end{array}$ & $\begin{array}{l}\text { PSem } \\
(\mathrm{mg})\end{array}$ & $\begin{array}{c}\text { Índice de } \\
\text { endogamia }\end{array}$ & $\begin{array}{c}\text { ERep } \\
\left(\mathrm{mg} \mathrm{g}^{-1}\right)\end{array}$ \\
\hline 98 & $13.1 \pm 1.0$ & $103 \pm 3$ & $86 \pm 1$ & $11 \pm 1$ & $3 \pm 0$ & $13.4 \pm 0.2$ & $0.21 \pm 0.03$ & $12 \pm 1$ \\
\hline 95 & $9.5 \pm 0.5$ & $98 \pm 3$ & $60 \pm 5$ & $12 \pm 2$ & $28 \pm 4$ & $10.4 \pm 0.2$ & $0.67 \pm 0.04$ & $13 \pm 2$ \\
\hline 92 & $8.0 \pm 0.5$ & $97 \pm 4$ & $40 \pm 4$ & $39 \pm 3$ & $21 \pm 3$ & $9.4 \pm 0.2$ & $0.33 \pm 0.04$ & $47 \pm 4$ \\
\hline 90 & $12.5 \pm 0.7$ & $107 \pm 2$ & $78 \pm 3$ & $11 \pm 2$ & $11 \pm 2$ & $12.8 \pm 0.4$ & $0.60 \pm 0.08$ & $11 \pm 2$ \\
\hline 84 & $11.1 \pm 1.1$ & $98 \pm 4$ & $57 \pm 3$ & $30 \pm 3$ & $13 \pm 1$ & $12.4 \pm 0.3$ & $0.33 \pm 0.03$ & $36 \pm 5$ \\
\hline 73 & $24.9 \pm 0.7$ & $128 \pm 2$ & $70 \pm 3$ & $11 \pm 2$ & $19 \pm 2$ & $15.9 \pm 0.3$ & $0.66 \pm 0.04$ & $9 \pm 1$ \\
\hline 61 & $11.1 \pm 0.5$ & $90 \pm 2$ & $75 \pm 1$ & $14 \pm 1$ & $11 \pm 1$ & $10.7 \pm 0.2$ & $0.43 \pm 0.04$ & $12 \pm 1$ \\
\hline 57 & $18.4 \pm 0.7$ & $125 \pm 3$ & $69 \pm 3$ & $18 \pm 2$ & $13 \pm 3$ & $12.3 \pm 0.2$ & $0.37 \pm 0.05$ & $15 \pm 2$ \\
\hline 51 & $24.8 \pm 0.8$ & $91 \pm 3$ & $34 \pm 3$ & $28 \pm 3$ & $38 \pm 3$ & $11.2 \pm 0.1$ & $0.57 \pm 0.04$ & $11 \pm 1$ \\
\hline 35 & $12.1 \pm 0.7$ & $93 \pm 2.7$ & $72 \pm 3$ & $15 \pm 2$ & $13 \pm 2$ & $11.4 \pm 0.2$ & $0.46 \pm 0.03$ & $13 \pm 1$ \\
\hline 34 & $21.6 \pm 1.7$ & $117 \pm 4$ & $74 \pm 3$ & $20 \pm 3$ & $6 \pm 1$ & $13.6 \pm 0.2$ & $0.26 \pm 0.05$ & $15 \pm 2$ \\
\hline 32 & $11.5 \pm 0.8$ & $104 \pm 3$ & $79 \pm 3$ & $11 \pm 2$ & $10 \pm 2$ & $12.3 \pm 0.3$ & $0.49 \pm 0.06$ & $12 \pm 2$ \\
\hline 3 & $10.3 \pm 0.4$ & $94 \pm 1.7$ & $65 \pm 3$ & $22 \pm 2$ & $13 \pm 2$ & $12.5 \pm 0.3$ & $0.35 \pm 0.03$ & $25 \pm 2$ \\
\hline 179 & $17.0 \pm 0.7$ & $126 \pm 3$ & $61 \pm 4$ & $16 \pm 2$ & $23 \pm 3$ & $12.5 \pm 0.1$ & $0.54 \pm 0.04$ & $15 \pm 2$ \\
\hline 168 & $17.9 \pm 0.4$ & $115 \pm 2$ & $58 \pm 2$ & $7 \pm 1$ & $35 \pm 2$ & $11.4 \pm 0.2$ & $0.83 \pm 0.02$ & $5 \pm 1$ \\
\hline 166 & $13.6 \pm 0.6$ & $97 \pm 4$ & $62 \pm 2$ & $12 \pm 2$ & $26 \pm 2$ & $11.2 \pm 0.3$ & $0.69 \pm 0.03$ & $10 \pm 1$ \\
\hline 133 & $17.9 \pm 0.6$ & $126 \pm 2$ & $85 \pm 1$ & $6 \pm 1$ & $9 \pm 1$ & $9.2 \pm 0.2$ & $0.64 \pm 0.05$ & $3 \pm 1$ \\
\hline 109 & $7.9 \pm 0.3$ & $106 \pm 4$ & $48 \pm 3$ & $26 \pm 2$ & $26 \pm 2$ & $10.5 \pm 0.3$ & $0.50 \pm 0.02$ & $37 \pm 2$ \\
\hline 105 & $18.4 \pm 0.4$ & $112 \pm 3$ & $47 \pm 3$ & $35 \pm 2$ & $17 \pm 2$ & $8.8 \pm 0.1$ & $0.32 \pm 0.03$ & $19 \pm 1$ \\
\hline 101 & $16.6 \pm 0.4$ & $127 \pm 3$ & $54 \pm 3$ & $15 \pm 2$ & $31 \pm 2$ & $10.7 \pm 0.2$ & $0.68 \pm 0.03$ & $12 \pm 1$ \\
\hline
\end{tabular}

$\mathrm{POA}=$ porcentaje de óvulos abortivos; PSLL = porcentaje de semillas llenas; PSV = porcentaje de semillas vanas; PSem $=$ peso de semilla; ERep = eficiencia reproductiva.

\section{Ensayo de germinación}

En germinación se encontraron diferencias $(\mathrm{P} \leq 0.01)$ entre árboles (Cuadro 3). El error experimental fue la principal fuente de variación para capacidad germinativa, mientras que la repetición fue la principal fuente de variación para valor pico. La capacidad germinativa media de las semillas de $P$. leiophylla fue $82.5 \%$, con un valor pico promedio de 8.5 semillas, el que varió de 4.6 en el árbol 32 a 11.4 en el árbol 90 (Cuadro 4). Las semillas del árbol 90 germinaron más rápidamente que el resto de los árboles, mientras las semillas del árbol 32 fueron las más lentas en germinar (Figura 1). Los valores promedios de capacidad germinativa, valor pico y valor germinativo fueron aglutinados en grupos diferentes por la prueba de Tukey (Cuadro 4).

Cuadro 3. Componentes de varianza para los parámetros germinativos de la semilla de un huerto semillero sexual de $P$. leiophylla Schiede ex Schltdl. \& Cham.

\begin{tabular}{lrrrr}
\hline Variables & $\sigma^{2}$ Total & \multicolumn{3}{c}{$\begin{array}{c}\text { Componentes de varianza } \\
\text { (en \% de } \sigma^{2} \text { Total) }\end{array}$} \\
\cline { 3 - 5 } & & $\sigma^{2} \dagger$ & $\sigma^{2}$ Arbol & $\sigma^{2}$ error \\
\hline Capacidad germinativa & 0.06 & 4.12 & $41.29 * *$ & 54.59 \\
Valor pico & 13.97 & 45.57 & $29.34 * *$ & 25.05 \\
Valor germinativo & 254.23 & 30.70 & $36.85 * *$ & 32.45 \\
\hline${ }^{\dagger} \sigma^{2} \mathrm{R}=$ varianza entre repeticiones. $* * \mathrm{P} \leq 0.01$. & &
\end{tabular}




\begin{tabular}{|c|c|c|c|c|c|c|}
\hline \multirow{2}{*}{$\begin{array}{c}\text { Árbol } \\
90\end{array}$} & \multicolumn{2}{|c|}{ Capacidad germinativa (\%) } & \multicolumn{2}{|c|}{ Valor pico } & \multicolumn{2}{|c|}{ Valor germinativo } \\
\hline & $97.8 \pm 1.0$ & $\mathrm{a}$ & $11.4 \pm 1.1$ & $\mathrm{a}$ & $44.2 \pm 4.1$ & $\mathrm{a}$ \\
\hline 95 & $96.4 \pm 1.3$ & $\mathrm{ab}$ & $11.1 \pm 1.0$ & $a b$ & $43.0 \pm 3.9$ & $a b$ \\
\hline 3 & $93.7 \pm 1.6$ & $a b c$ & $10.8 \pm 1.0$ & $a b c$ & $40.8 \pm 3.2$ & $a b c$ \\
\hline 105 & $93.0 \pm 1.5$ & $a b c$ & $10.5 \pm 1.0$ & abcd & $39.3 \pm 3.3$ & abcd \\
\hline 168 & $89.7 \pm 5.0$ & abcd & $10.9 \pm 1.5$ & $a b c$ & $40.5 \pm 5.9$ & $a b c$ \\
\hline 57 & $91.0 \pm 2.5$ & abcd & $9.9 \pm 0.8$ & abcdef & $37.0 \pm 3.4$ & abcde \\
\hline 98 & $87.3 \pm 5.5$ & abcd & $7.3 \pm 0.8$ & fghi & $26.6 \pm 3.8$ & defghi \\
\hline 179 & $87.3 \pm 2.4$ & abcde & $8.3 \pm 0.6$ & cdefegh & $29.6 \pm 2.5$ & cdefgh \\
\hline 166 & $85.5 \pm 3.4$ & abcde & $9.8 \pm 1.0$ & abcdef & $34.8 \pm 4.3$ & abcdef \\
\hline 92 & $85.7 \pm 3.6$ & bcde & $8.6 \pm 0.7$ & bcdefg & $30.5 \pm 2.6$ & bcefg \\
\hline 51 & $84.3 \pm 3.9$ & bcde & $10.0 \pm 1.0$ & abcde & $35.6 \pm 4.0$ & abcde \\
\hline 109 & $82.8 \pm 2.7$ & cde & $8.9 \pm 0.6$ & abcdef & $29.7 \pm 2.5$ & cdefgh \\
\hline 84 & $80.0 \pm 2.5$ & cdef & $8.6 \pm 0.8$ & bcdefg & $28.3 \pm 3.3$ & defgh \\
\hline 34 & $76.7 \pm 3.2$ & def & $5.8 \pm 0.4$ & hij & $18.3 \pm 1.6$ & ghij \\
\hline 61 & $77.5 \pm 2.7$ & def & $8.0 \pm 0.7$ & defgh & $25.4 \pm 2.6$ & efghi \\
\hline 133 & $76.7 \pm 6.2$ & def & $6.1 \pm 0.7$ & ghi & $19.6 \pm 3.0$ & ghij \\
\hline 73 & $72.9 \pm 3.1$ & ef & $7.4 \pm 0.8$ & efghi & $22.3 \pm 3.0$ & fghij \\
\hline 101 & $71.0 \pm 3.2$ & ef & $5.7 \pm 0.4$ & hij & $16.7 \pm 1.6$ & hij \\
\hline 35 & $61.5 \pm 3.1$ & $\mathrm{f}$ & $5.4 \pm 0.5$ & $\mathrm{ij}$ & $13.7 \pm 1.6$ & $\mathrm{ij}$ \\
\hline 32 & $58.6 \pm 4.5$ & $\mathrm{f}$ & $4.6 \pm 0.4$ & $\mathrm{j}$ & $11.2 \pm 1.5$ & $\mathrm{j}$ \\
\hline
\end{tabular}

Medias con letras iguales en cada columna, no son estadísticamente diferentes (Tukey, 0.01).

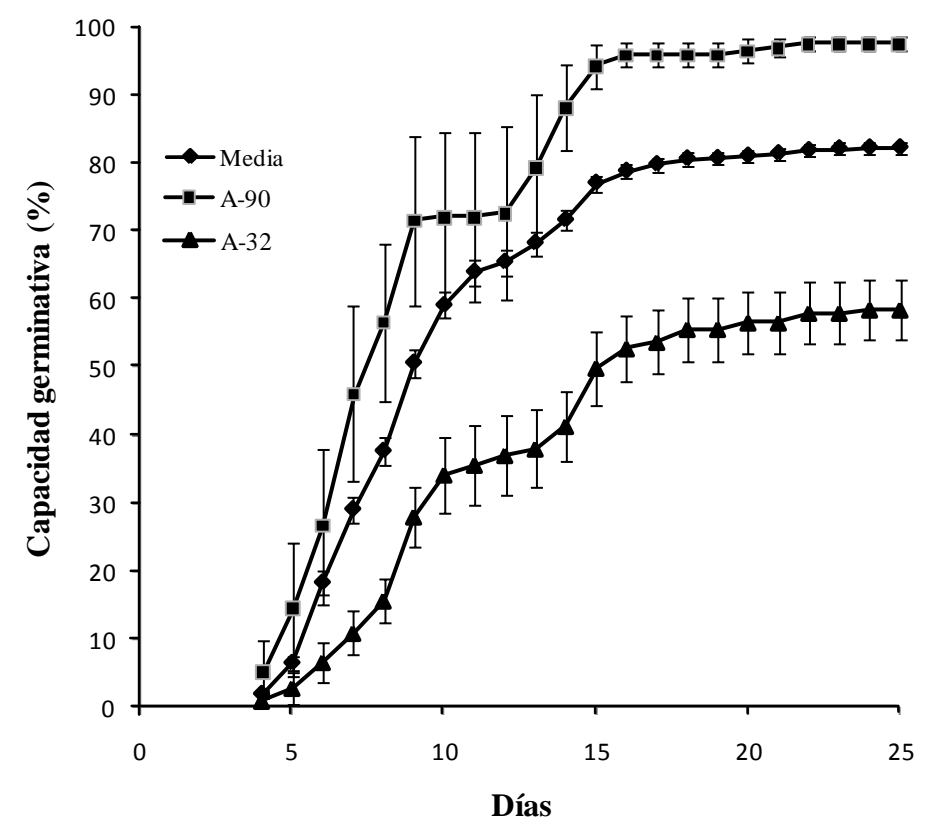

Figura 1. Germinación acumulada media (barras verticales indican el error estándar) de los árboles de Pinus leiophylla Schiede ex Schltdl. \& Cham., y medias de los árboles (A-90 y A-32) con valores extremos.

\section{DISCUSIÓN}

Los resultados mostraron alta variación genética en las características reproductivas. El número potencial de semillas (108) de los estróbilos de P. leiophylla fue el doble que el reportado por Delgado (1994) para la misma especie (53), quizás debido a que Delgado (1994) sólo incluyó árboles de una población natural mientras que en el presente estudio se evaluaron árboles de 16 poblaciones distribuidas en la porción central del Eje Neovolcánico; es 
decir, los individuos del huerto semillero constituyen una muestra más representativa de la variación natural, la cual incluye variación genética entre y dentro de poblaciones, así como la ambiental y del componente interacción genotipo x ambiente (Hart y Clark, 2007). Aunque los estróbilos de $P$. leiophylla son de menor tamaño que los de $P$. greggii Engelm. y $P$. pinea L., el número potencial de semillas de $P$. leiophylla fue muy similar al potencial de esas dos especies, 104 y 99 semillas por estróbilo, respectivamente según reportaron López-Upton y Donahue (1995) y Ganatsas et al. (2008).

El porcentaje promedio de óvulos abortivos (63.7\%) que se registró en $P$. leiophylla fue mayor al reportado (34 \%) por Mápula-Larreta et al. (2007) en Pseudotsuga menziesii (Mirb.) Franco. Según Fowler y Park (1983) y Owens et al. (2005), la escasez e inviabilidad del polen, y la autofecundación son las causas principales del aborto de semillas de coníferas. La viabilidad del polen no se evaluó en el presente estudio. El alto porcentaje de óvulos abortivos registrados en los estróbilos de $P$. leiophylla pudo deberse a una producción escasa de polen; como sólo un tercio de los árboles produjeron estróbilos femeninos, es posible que la producción de estróbilos masculinos también haya sido reducida. La escasa producción de polen incrementa la probabilidad de autopolinización del mismo árbol.

La autofecundación puede ser la principal causa de semillas vanas en estróbilos de $P$. leiophylla. En otros estudios en los que se efectuó polinización controlada en coníferas, se encontraron porcentajes de semillas vanas mayores de $90 \%$ en estróbilos autopolinizados (Coles y Fowler, 1976; Fowler y Park, 1983; Owens et al., 2005). La autofecundación aumenta la frecuencia de genotipos constituidos por genes recesivos que provienen de un ancestro común, los cuales en estado homocigótico pueden manifestar efectos deletéreos sobre el embrión de la semilla y producir un número alto de semillas vanas (Allen y Owens, 1972). En menor medida, el polen de otra especie del género Pinus y el ataque de insectos también pueden influir en el número de semillas vanas en coníferas (Owens et al., 2005). En los jardines aledaños al huerto semillero crecen árboles de otras especies de pino; sin embargo, la probabilidad que el polen de esos árboles influya en el número de semillas vanas en el huerto semillero de $P$. leiophylla es muy baja, debido al aislamiento por distancia y las barreras que representan los edificios que rodean al huerto semillero.

En el análisis de semilla no se detectó ataque de insectos, por lo que el alto número de semillas vanas y el alto índice de depresión endogámica $(0.50)$ es consecuencia de la endogamia por autofecundación, la cual pudo tener origen en el hecho que los pocos árboles que produjeron estróbilos femeninos fueron los mismos que produjeron estróbilos masculinos. En comparación con otras especies, el índice de endogamia (0.50) en $P$. leiophylla fue mayor que el encontrado en $P$. rigida Mill. (0.35) por Mosseler et al. (2004) pero menor a los índices (0.61 y 0.80 , respectivamente) reportados por FloresLópez et al. (2005) y Mápula-Larreta et al. (2007) para Picea mexicana Martínez y Pseudotsuga menziesii; estas dos especies mexicanas crecen en poblaciones naturales fragmentadas constituidas por un número reducido de individuos.

En el género Pinus la mayoría de semillas llenas es producto de polinización cruzada (Mitton, 1992), y sólo una proporción baja de semilla llena proviene de autopolinización. Por ejemplo, en estróbilos con autopolinización de $P$. contorta Dougl. ex Loud. var. latifolia Engelm, Owens et al. (2005) encontraron $10 \%$ de semillas llenas. Un estudio de isoenzimas en semillas llenas de $P$. albicaulis Engelm. reveló una tasa de cruzamiento de $73 \%$ (Krakowski et al., 2003), lo cual indicó que $27 \%$ de las semillas llenas de esta especie fue producto de endogamia.

El número de semillas llenas por estróbilo y el peso promedio de semillas son importantes para determinar la cantidad de germoplasma requerido en los programas de plantaciones. Los resultados aquí obtenidos indican que el número promedio de semillas de $P$. leiophylla en $1 \mathrm{~kg}$ es 86200 , que se producen en alrededor de 4537 estróbilos (19 semillas llenas por estróbilo). Perry (1991) reportó 85 000 semillas por $\mathrm{kg}$ en $P$. leiophylla.

La eficiencia reproductiva, evaluada mediante el cociente del peso de la semillas por estróbilo entre el peso seco del estróbilo, fue baja en comparación con otras coníferas. Por ejemplo, en poblaciones naturales de Pinus rigida Mill., Picea rubens Sarg., Picea mexicana y Pseudotsuga menziesii, la eficiencia reproductiva fue de $3.3,55.3,23.7$ y $29.6 \mathrm{mg} \mathrm{g}^{-1}$, respectivamente (Mosseler et al., 2000; Mosseler et al., 2004; Flores-López et al., 2005; Mápula-Larreta et al., 2007). La eficiencia reproductiva está influenciada por el peso y número de semillas llenas por estróbilo, y es un indicador de la proporción de energía que un árbol dedica a la producción de semilla para la generación de nuevos individuos, más que a la biomasa del estróbilo. Se esperaría que en años en que la producción de polen sea abundante, aumente el número de semillas llenas y también la eficiencia reproductiva. Además, podrían aplicarse prácticas de manejo a los árboles del huerto para promover la producción de estróbilos. 
Los valores promedios de capacidad germinativa, el valor pico y el valor germinativo de las semillas en el presente estudio fueron altos, lo que indica alta calidad de la semilla llena cosechada en el huerto semillero de $P$. leiophylla. Delgado (1994) reportó 93 \% de germinación en semilla colectada en el centro del Estado de Michoacán, para esta misma especie. Aunque el ataque de hongos no fue evidente durante la germinación de la semilla, es posible que bacterias y virus hayan impedido la germinación de la semilla que no logró germinar. Los altos parámetros germinativos promedio aquí obtenidos revelaron que la mayoría de la semilla de $P$. leiophylla no presenta latencia, aunque sería necesario realizar un estudio detallado para vislumbrar la causa de la variación en la capacidad germinativa entre árboles de este huerto semillero. Asimismo, la depresión endogámica puede influir en la viabilidad del embrión de semillas llenas de $P$. leiophylla como consecuencia de autofecundación. Remington y O'Malley (2000) encontraron un alelo que reduce en $44 \%$ la viabilidad de los embriones homocigóticos de semilla de $P$. taeda $\mathrm{L}$.

Al igual que en capacidad germinativa, se encontró variación genética en valor pico y valor germinativo de la semilla evaluada de $P$. leiophylla, pero sus promedios indican alta calidad de la semilla llena, ya que ambas características miden el vigor de la semilla (Czabator, 1962; Kolotelo et al., 2001). La contribución de los árboles de $P$. leiophylla a la variación total para capacidad germinativa, valor pico y el valor germinativo (41.3, 29.3 y $26.9 \%$, respectivamente) fue alto en comparación con los valores encontrados en otras especies de coníferas. Por ejemplo, en árboles de Pinus pinceana Gordon se reportó que contribuyeron a la variación total con 16.5 , 23.7 y $21.7 \%$, para capacidad germinativa, valor pico y valor germinativo, respectivamente (Ramírez-Herrera et al., 2008).

\section{CONCLUSIONES}

Se encontraron altos niveles de variación en las características reproductivas evaluadas. Los árboles constituyeron la principal fuente de variación en la mayoría de las características reproductivas en estróbilos de Pinus leiophylla. El alto índice de endogamia indicó altos niveles de autofecundación en los árboles del huerto semillero. Con base en las características germinativas, se considera que la semilla llena recolectada en el huerto semillero sexual de $P$. leiophylla es de alta calidad.

\section{BIBLIOGRAFÍA}

Allen G S, J N Owens (1972) The Life History of Douglas-fir. Canadian Forest Service, Ottawa, ON, 139 p.
Burczyka J, A Lewandowskib, W Chalupka (2004) Local pollen dispersal and distant gene flow in Norway spruce (Picea abies [L.] Karst.). For. Ecol. Manage. 197:39-48.

Cherry M L, T S Anekonda, M J Albrecht, G T Howe (2007) Flower stimulation in young miniaturized seed orchards of Douglas-fir (Pseudotsuga menziesii). Can. J. For. Res. 37:1-10.

Coles J F, D P Fowler (1976) Inbreeding in neighbouring trees in two white spruce populations. Silvae Genet. 25:29-34.

Crnokrak P, S C H Barrett (2002) Perspective: purging the genetic load: a review of the experimental evidence. Evolution 56:2347-2358.

Czabator F J (1962) Germination value: An index combining speed and completeness of pine seed germination. For. Sci. 8:386-396.

Delgado V P (1994) Evaluación de la capacidad productiva y eficiencia de semillas para tres especies del género Pinus ( $P$. montezumae Lamb., $P$. pseudostrobus Lind. y $P$. leiophylla Schl. \& Cham.), en la zona boscosa de Nuevo San Juan Parangaricutiro, Michoacán, México. Bol. Soc. Bot. Méx. 54:267-274.

Dirección General de Geografía (1983) Carta edafológica Chalco E14B31 escala 1:50000. Coordinación de los Servicios Generales de los Servicios Nacionales e Informática. México, D.F.

Flores-López C，J López-Upton，J J Vargas-Hernández (2005) Indicadores reproductivos en poblaciones naturales de Picea mexicana Martínez. Agrociencia 39:117-126.

Fowler D P, Y S Park (1983) Population studies of white spruce. I. Effects of self pollination. Can. J. For. Res. 13:1133-1138.

Ganatsas P, M Tsakaldimi, C Thanos (2008) Seed and cone diversity and seed germination of Pinus pinea in Strofylia Site of the Natura 2000 Network. Biodiv. Conserv. 17:2427-2439.

Griffin A R (1990) Effects of inbreeding on growth of forest trees and implications for management of seed supplies for plantation programs. In: Reproductive Ecology of Tropical Forest Plants. K S Bawa, M Hadley (eds). Parthenon Publishing. London, UK. pp:355-374.

Hart D L, A G Clark (2007) Principles of Population Genetics. 4th ed. Sinauer Associates, Inc, Publishers. Sunderland, Massachusetts, USA. $652 \mathrm{p}$.

Kolotelo D, E V Steenis, M Bennett, D Trotter, Y J Dennis (2001) Seed Handling Guidebook. Ministry of Forests, Tree Improvement Branch. British Columbia, Canada. $106 \mathrm{p}$.

Krakowski J, S N Aitken, Y A El-Kassaby (2003) Inbreeding and conservation genetics in whitebark pine. Conserv. Genet. 4:581-593.

López-Upton J, J K Donahue (1995) Seed production of Pinus greggii Engelm. in natural stands in Mexico. Tree Planters Notes 46:86-92.

Mápula-Larreta M, J López-Upton, J J Vargas-Hernández, A Hernández-Livera (2007) Reproductive indicators in natural populations of Douglas-fir in Mexico. Biodiv. Conserv. 16:727742.

Martínez-Trinidad T, J J Vargas-Hernández, A Muñoz-Orozco, J López-Upton (2002) Respuesta al déficit hídrico en Pinus leiophylla: consumo de agua y crecimiento en plántulas de diferentes poblaciones. Agrociencia 36:365-376.

Mitton J B (1992) The dynamic mating systems in conifers. New For. 6:197-216

Mosseler A, J E Major, J D Simpson, B Daigle, K. Lange, Y S Park, K H Johnsen, O P Rajora (2000) Indicators of population viability in red spruce, Picea rubens. I. Reproductive traits and fecundity. Can. J. Bot. 78:928-940.

Mosseler A, O P Rajora, J E Major, K H Kim (2004) Reproductive and genetic characteristics of rare, disjunct pitch pine populations at the northern limits of its range in Canada. Conserv. Genet. 5:571-583. 
Owens J N, J Bennett, S L'Hirondelle (2005) Pollination and cone morphology affect cone and seed production in lodgepole pine seed orchards. Can. J. For. Res. 35:383-400.

Perry J P (1991) The Pines of Mexico and Central America. Timber Press, Portland, Oregon, USA. 231 p.

Ramírez-Herrera C, T Beardmore, J Loo (2008) Overcoming dormancy of Pinus pinceana seeds. Seed Sci. Technol. 36:1-20.

Remington D L, D M O'Malley (2000) Evaluation of major genetic loci contributing to inbreeding depression for survival and early growth in a selfed family of Pinus taeda. Evolution 54:15801589.
SAS Institute (2003) SAS version 9.1.3 for Windows. SAS Institute, Inc. Cary, NC, USA.

Sokal R R, J Rohlf (1981) Biometry: The Principles of Practice of Statistics in Biological Research. W.H Freeman and Company. San Francisco, USA. 776 p.

Vander Wall S B (1992) The role of animals in dispersing a "winddispersed" pine. Ecology 73:614-621.

White T L, W T Adams, D B Neale (2007) Forest Genetics. CABI Publishing, Cambridge, MA USA. 682 p.

Williams C G (2008) Selfed embryo death in Pinus taeda: a phenotypic profile. New Phytol. 178:210-222. 